lâm sàng, kiểu gen của bệnh $\mathrm{HbH}$ và chẩn đoán trước sinh bênh anpha-thalassemia, Luận văn Tiến sĩ y hoc, Trường Đai hoc Y Hà Nội.

7. Nguyễn Thi Thu Hà (2017), Nghiên cứu đăc điểm đôt biến gen globin và theo dõi điêuu tri thải sắt ở bệnh nhân thalassemia tại Viện Huyết học -
Truyền máu Trung ương giai đoạn 2013 - 2016, Luận văn Tiến sĩ y học, Trường Đại học Y Hà Nội.

8. Nguyển Hoàng Nam, Lý Thỉ Thanh Hà, Dướng Bá Trức và CS (2017). Đột biến gen ở bệnh nhân thalassemia tại bệnh viện Nhi Trung Ướng. Tạp Chí Nhi Khoa, 10(5), 46-51.

\title{
YẾU TỐ TIÊN LƯỢNG SINH NON SAU PHẪU THUÂT LASER QUANG ĐÔNG ĐIỀU TRI HộI CHỨNG TRUYỀN MÁU SONG THAI TẠI BÊ̂NH VIỆN PHỤ SẢN HÀ NộI
}

\author{
Phan Thị Huyền Thương ${ }^{1,2}$, Nguyễn Duy Ánh ${ }^{1,2}$, Hồ Sỹ Hùng², \\ Nguyễn Thị Sim ${ }^{1}$, Nguyễn Thị Thu Hà ${ }^{1}$, Trương Quang Vinh ${ }^{3}$
}

\section{TÓM TẮT}

Mục tiêu: Xác định yếu tố tiên lượng nguy cơ sinh non sau phẫu thuật laser quang đồng điều trị hội chứng truyền máu song thai (HCTMST). Đối tượng và phương pháp nghiên cứu: Nghiên cứu can thiệp không đối chứng, từ tháng 10 năm 2019 đến tháng 11 năm 2020, 21 thai phụ được chẩn đoán HCTMST giai đoạn II - IV theo phân loại Quintero, tuổi thai từ 16 26 tuần được phâuu thuật laser đông mạch máu dây rốn chọn lọc điều trị HCTMST. Kết quả: Tuổi thai trung bình lúc sinh là $34,70 \pm 4,33$, tuần thai thai giữ thêm trung bình từ lúc phẫu thuật 12,97 tuân. Trên $50 \%$ thai phụ đẻ non dưới 37 tuần, $31 \%$ đẻ non dưới 34 tuân. Nguy cơ sinh non trước 34 tuần sau phẫu thuật tăng lên 4,33 lần nếu tuần thai phẫu thuật trên 22 tuân, tương tự nguy cơ sinh non tăng lên hớn 8,67 lần nếu chiều dài cổ tử cung 48 giờ sau phẫu thuật giảm trên trên $9,5 \%$. Tỷ lệ sống của sớ sinh sau phấu thuật là 90,48\%. Sau phẫu thuật có 2 ca thai lưu trong vòng 7 ngày sau phẫu thuật chiếm $6,06 \%$, không ghi nhận biến chứng trong phẫu thuật và biến chứng me sau phẫu thuật. Kết luận: Tuânn tuổi thai lúc phẫu thuật và thay đổi chiều dài cổ tử cung sau phẫu thuật 48 giờ là yếu tố có thể tiên lượng nguy cơ đẻ non sau phẫu thuật.

Tư khoá: Hội chứng truyền máu song thai, song thai, sinh non, phẫu thuật, laser.

\section{SUMMARY \\ PROGNOSTIC FACTORS OF PRETERM \\ BIRTH AFTER LASER UMBILICAL CORD ABLATION FOR TWIN-TWIN TRANSFUSION SYNDROME AT HANOI OBSTETRICS AND GYNECOLOGY HOSPITAL \\ Objectives: To evaluate the prognostic factors to}

${ }^{1}$ Bệnh viện Phụ sản Hà Nội

2Bộ môn Phụ Śán - Trướng Đai hoc Y Hà Nôi

${ }^{3}$ Trường Đại hoc Y Dước - Đại Học Quốc gia Hà Nội

Chịu trách nhiệm chính: Phan Thị Huyền Thương

Email: phanhuyenthuong@gmail.com

Ngày nhân bài: 10.9.2021

Ngày phản biện khoa học: 4.11.2021

Ngày duyệt bài: 15.11.2021 the risk of preterm birth after laser umbilical cord ablation in the treatment of twin-twin transfusion syndrome (HCTMST). Methods: This was a prospective study, data collected from October 2019 to November 2020 at Fetal Medicine center in HOGH. Twenty-one twins with a diagnosis of HCTMST stage II, III, IV before 26 gestations according to Quintero classification performed selected umbilical cord laser ablation. Results: The mean gestational age at birth was $34,70 \pm 4,33$ weeks, the average time of additional pregnancy retention after surgery was 12,97 weeks. The rate of preterm birth under 37 weeks was over $50 \%, 31 \%$ of premature birth under 34 weeks. The risk of preterm birth before 34 weeks of surgery increased by 4,33 times if the gestational week was more than 22 weeks. Similarly, the risk of preterm birth increased more than 8,67 times if the change in cervical length 48 hours after surgery was more than $9,5 \%$. The survival rate of newborns after surgery was $90,48 \%$. There were 2 stillbirths within 7 days after the operation, accounting for $6,06 \%$, no intraoperative complications, and maternal complications after surgery were recorded. Conclusion: Gestational week at surgery and change in cervical length 48 hours after surgery are prognostic factors for the risk of preterm delivery after surgery.

Key words: Twin - Twin transfusion sydrome, twin, preterm birth, surgery, laser.

\section{I. ĐẶT VẤN ĐỀ}

Hội chứng truyền máu song thai (HCTMST) chiếm khoảng $10-15 \%$ các trường hợp song thai một bánh rau hai buồng ối [1]. Phẩu thuật laser quang đông với hai kỹ thuật laser đông các cầu nối mạch và laser đông mạch máu dây rốn chọn lọc đã trở thành phương pháp lựa chọn đâuu tay trong điêu trị HCTMST [2], [3]. Tuy nhiên, phẫu thuật này có liên quan đến việc tăng nguy cơ sinh non với tuổi thai trung bình khi sinh từ 29-33 tuần [2], [4]. Sinh non bên cạnh gây tăng chi phí chăm sóc trẻ sinh non còn là yếu tố quan trọng nhất liên quan trực tiếp đến khả năng sống sót sơ sinh và ảnh hưởng đến các biến chứng 
thần kinh lâu dài sau phẫu thuật laser quang đông điêu trị HCTMST. Ngoài ra sinh non làm tăng nguy cơ tai biến thai kỳ và ảnh hướng đến tâm lý cho người mẹ [1], [2]. Một số yếu tố có thể ảnh hưởng đến sinh non gồm các biến số trước phẫu thuật như tiền sử sinh non trước và chiều dài cổ tử cung, các biến số phẫu thuật bao gồm thời gian phẩu thuật, lượng ối rút ra ở buồng đa ối và các biến số sau phẫu thuật như tách màng ối, vỡ ối non [4]. Ngay nay việc xác định yếu tố nguy cơ gây tăng tình trạng sinh non sau phẫu thuật laser quang đông đang là một câu hỏi luôn được quan tâm và việc giảm tỷ lệ sinh non, kéo dài tuổi thai cũng là một thách thức lớn cho các nhà sản khoa. Mục tiêu của nghiên cứu là xác định yếu tố tiên lượng nguy cơ sinh non sau phẫu thuật laser quang đông điều trị hội chứng truyền máu song thai

\section{II. ĐỐI TƯỢNG VÀ PHƯƠNG PHÁP NGHIÊN CỨU}

Đối tượng nghiên cứu. Nghiên cứu can thiêp không đối chứng. Thai phư được phẫu thuật laser quang đông với kỹ thuật đông mạch máu dây rốn chọn lọc tại Bệnh viện Phụ sản Hà Nội từ tháng 9 năm 2019 đến tháng 11 năm 2020. Nghiên cứu này đã được phê duyêt bởi Hội đồng đạo đức (IRB) của Trường Đại học $Y$ Hà Nội (IRB số NCS25 / HMU-IRB).

Chúng tôi thu nhận những thai phụ HCTMST tuổi thai từ 16 đên 26 tuần được chẩn đoán: HCTMST giai đoạn III hoặc IV; HCTMST có kèm sIUGR hoặc khi không thực hiện được kỹ thuật laser đông các cầu nối mạch, như khoảng cách giữa hai gốc dây rốn gần nhau. Tất cả thai phụ được giải thích trước phẫu thuâat và đồng ý tham gia nghiên cứu và thực hiện phẫu thuật.

Chẩn đoán HCTMST được thực hiện theo tiêu chí ISOUG [5], phân giai đoạn theo nghiên cứu của Quintero et al [6].

Chúng tôi loại trừ các trường hợp sinh ba bằng HCTMST, HCTMST thực hiện phẫu thuật đông các cầu nối mạch và các trường hợp me có chống chỉ định phẫu thuật như bệnh lý tim mạch hoặc trong tình trang võ ối, chuyển dạ.

Qui trình phấu thuật. Phương pháp vô cảm được thực hiên bằng cách gây tê tĩnh mạch và gây tê tai chố bằng Lidocain $1 \%$. Các thai phụ được phẩu thuật bằng kỹ thuâat laser đông mạch máu dây rốn chọn lọc. Sau đầy nước ối được rút ra cho đến khi góc ối sâu nhất (MVP) đạt mức bình thường $6-7 \mathrm{~cm}$ [3].

Theo dõi sau phẩu thuật ở thời điểm 24h, 48h, 7 ngày sau mổ và 2 tuần một lần cho đến khi sinh bằng và khám lâm sàng siêu âm.
Theo dõi sản khoa và sơ sinh được thực hiện bởi các bác sĩ sản khoa và sơ sinh có kinh nghiệm. Phương thực sinh được quyết định theo chỉ đinh sản khoa.

Kết quả. Kết cục chính là tỷ lệ sống sót và yếu tố tiên lượng sinh non. Các biến số kết cục phụ là tuổi thai khi sinh, khoảng thời gian giữa điều trị laser và sinh ở những thai có ít nhất một trẻ sơ sinh sống, chiều dài cổ tử cung, cân nặng lúc sinh. Sơ sinh sống được định nghĩa là sơ sinh sống đến khi xuất viện. Sự giảm chiều dài cổ tử cung sau phẫu thuật được tính bằng tỷ số giữa hiệu số giữa chiều dài cố tử cung trước khi phẫu thuật trừ chiều dài cổ tử cung tại thời điểm kiểm tra hậu phẫu, tất cả chia cho chiều dài cổ tử cung trước khi phẫu thuật

Phân tích thống kề. Dữ liệu được thu thập và quản lý bằng phần mềm Redicap và phân tích bằng phần mềm STATA 16.0.

\section{KẾT QUẢ NGHIÊN CỨU}

Bảng 1: Đặc điểm chung ( $n=21)$

\begin{tabular}{|c|c|}
\hline Tuối me (năm) & $27,0 \pm 4,3(18-37)$ \\
\hline \multicolumn{2}{|c|}{ Nơi sống: n (\%) } \\
\hline Miền Bắc & $19 / 21(90,48)$ \\
\hline Miền Trung & $1 / 21(4,76)$ \\
\hline Miên Nam & $1 / 21(4,76)$ \\
\hline \multicolumn{2}{|c|}{ Tiền sử bệnh lý mẹ trước phâu thuật: n(\%) } \\
\hline Viêm ầm đạo & $3 / 21(14,29)$ \\
\hline Đái tháo đường & $1 / 21(4,76)$ \\
\hline Sinh non & $0 / 21(0,00)$ \\
\hline \multicolumn{2}{|c|}{ Vị trí bánh rau: $\mathbf{n}(\%)$} \\
\hline Mặt trước & $8 / 21(38,10)$ \\
\hline Mặt sau & $13 / 21(61,90)$ \\
\hline SIUGR & $12 / 21(57,14)$ \\
\hline Chiều dài CTC $(\mathrm{cm})$ & $36,03 \pm 7,40(18,1-45)$ \\
\hline $\begin{array}{c}\text { Góc ối sâu nhất thai } \\
\text { đa ối (ml) }\end{array}$ & $\begin{array}{l}94,86 \pm 13,33 \\
(73-125)\end{array}$ \\
\hline $\begin{array}{c}\text { Góc ối sâu nhất thai } \\
\text { thiểu ối (ml) }\end{array}$ & $\begin{array}{l}10,68 \pm 7,31 \\
(0-20)\end{array}$ \\
\hline \multicolumn{2}{|c|}{ Giai đoạn HCTMST: n (\%) } \\
\hline Giai đoạn II & $18 / 21(85,71)$ \\
\hline Giai đoạn IV & $3 / 21(14,29)$ \\
\hline $\begin{array}{l}\text { Tuần thai phâuu thuật } \\
\text { (tuân) }\end{array}$ & $\begin{array}{c}20,30 \pm 2,32 \\
(16,57-28,86)\end{array}$ \\
\hline \multicolumn{2}{|c|}{$\begin{array}{c}\text { Nguyên nhân phầu thuâât laser } \\
\text { quang đông: n (\%) }\end{array}$} \\
\hline sIUGR & $12 / 21(57,14)$ \\
\hline $\begin{array}{c}\text { Khoảng cách gốc hai dây } \\
\text { rốn gần nhau }\end{array}$ & $6 / 21(28,57)$ \\
\hline HCTMST giai đoạn IV & $3 / 21(14,29)$ \\
\hline
\end{tabular}

Nhân xét: Tuối thai trung bình trước phẫu thuật là 20,30 tuần, phân loại giai đoạn của HCTMST trước phẫu thuật chúng tôi chỉ có giai đoạn II $(85,71 \%)$ và giai đoạn IV $(14,29 \%)$, hơn 
50\% có tình trạng sIŨRG kèm theo, đây cũng là nguyên nhân chính dẫn đến chỉ định phẫu thuật đông dây rốn chọn lọccủa các đối tượng nghiên cứu.

Bảng 2: Kềt quả phẫu thuật laser quang đông $(n=21)$

\begin{tabular}{|c|c|}
\hline $\begin{array}{l}\text { Phương pháp vô cảm: n } \\
(\%) \text { mê tĩnh mạch }\end{array}$ & $33(100)$ \\
\hline Thời gian phẫu thuật (phút) & $\begin{array}{c}39,52 \pm 9,21 \\
(30-60)\end{array}$ \\
\hline $\begin{array}{l}\text { Lượng ối hút ra thai đa ối } \\
\qquad(\mathrm{ml})\end{array}$ & $\begin{array}{c}533,33 \pm 224,35 \\
(300-1200)\end{array}$ \\
\hline $\begin{array}{l}\text { Biến chứng trong phâu } \\
\text { thuật: } \mathrm{n}(\%)\end{array}$ & $0(0)$ \\
\hline $\begin{array}{c}\text { Biến chứng mẹ sau phâu } \\
\text { thuật: } n(\%)\end{array}$ & $0(0)$ \\
\hline Thời gian nằm viện (ngày) & $5,42 \pm 3,96(3-20)$ \\
\hline \multicolumn{2}{|c|}{ Biến chứng sơ sinh: n (\%) } \\
\hline $\begin{array}{c}\text { Thai lưu } 7 \text { ngày sau phâu } \\
\text { thuật }\end{array}$ & $2 / 33(6,06)$ \\
\hline \multicolumn{2}{|c|}{ Chiều dài cổ tử cung (cm) } \\
\hline Trước phẫu thuật & $\begin{array}{l}36,03 \pm 7,40 \\
(18,1-45)^{*}\end{array}$ \\
\hline 48h sau phẫu thuật & $\begin{array}{c}34,06 \pm 9,46 \\
(7-45)^{* *}\end{array}$ \\
\hline 7 ngày sau phẫu thuật & $\begin{array}{c}35,17 \pm 7,11(14,6- \\
45,7)^{* * *}\end{array}$ \\
\hline $\begin{array}{c}\text { Thời gian giữ thai thêm sau } \\
\text { phẫu thuật }\end{array}$ & $\begin{array}{l}12,97 \pm 6,87 \\
(0,29-20,86)\end{array}$ \\
\hline $\begin{array}{l}\text { Tuối thai TB lúc sinh } \\
(n=19) n(\%)\end{array}$ & $\begin{array}{l}34,70 \pm 4,33 \\
(25,4-39,43)\end{array}$ \\
\hline$<37$ tuần & $10 / 19(52,63)$ \\
\hline Z 34 tuân & $6 / 19(31,57 \%)$ \\
\hline \multicolumn{2}{|c|}{ Cách thức sinh: n (\%) } \\
\hline
\end{tabular}

\begin{tabular}{|c|c|}
\hline Đường âm đạo & $11(57,89)$ \\
\hline Mố lấy thai & $8(42,11)$ \\
\hline $\begin{array}{r}\mathrm{p}(*)(* *)>0.05 ; \mathrm{p} \\
(* * *)>0.05(\mathrm{l}\end{array}$ & $\begin{array}{l}>0.05 ; \mathrm{p}\left({ }^{* *}\right) \\
\text { itney test) }\end{array}$ \\
\hline
\end{tabular}

Nhânn xét: Tuổi thai trung bình khi sinh là $34,70 \pm 4,33$ tuân. Chúng tôi giữ thai trung bình thêm 12,97 tuân sau phấu thuât. Tỷ lê sinh non dưới 34 tuân là $31,57 \%$. Chúng tôi không ghi nhận biến chứng nào trong quá trình phẫu thuật và biến chứng mẹ sau phẫu thuật. Về biến chứng thai kỳ chúng tôi chỉ ghi nhận được 2 ca thai lưu (6.06\%) trong vòng 7 ngày sau phẫu thuật. Sau phẫu thuật chúng tôi ghi nhận được có giảm chiều dài cổ tử cung tại thời điểm sau phẫu thuật 48 giờ và sau phâuu thuật 7 ngày, tuy nhiên sự thay đổi này chưa có ý nghĩa thống kê với $\mathrm{p}<0.05$ (Mann-Whitney test).

Bảng 3: Kết quả sớsinh (n = 19)

\begin{tabular}{|c|c|}
\hline Apgar & \\
\hline 1 phút & $7,16 \pm 1,38(3-8)$ \\
\hline 5 phút & $8,21 \pm 1,36(4-9)$ \\
\hline Cân nặng sơ sinh(gr) & $\begin{array}{c}2281,58 \pm 734,13 \\
(750-3250)\end{array}$ \\
\hline$>2500 \mathrm{gr}$ & $10(52,63)$ \\
\hline $1500-2500 \mathrm{gr}$ & $5(26,32)$ \\
\hline $1000-1500 \mathrm{gr}$ & $3(15,79)$ \\
\hline$<1000 \mathrm{gr}$ & $1(5,26)$ \\
\hline $\begin{array}{c}\text { Karyotype: } \mathrm{n}(\%) \\
\text { Bình thường }\end{array}$ & $21(100)$ \\
\hline Sơ sinh sống & $19 / 21(90,48)$ \\
\hline
\end{tabular}

Nhân xét: Tỷ lê sống sơ sinh sau phầu thuật là $90,48 \%$, hơn $50 \%$ có tình trạng nhẹ cân kèm theo

Bảng 4: Môi liên quan giữa đẻ non 34 tuân với các yếu tố $(n=19)$

\begin{tabular}{|c|c|c|c|c|}
\hline \multirow{2}{*}{ Yếu tố } & \multicolumn{4}{|c|}{ Đẻ non dưới 34 tuần } \\
\hline & $>=34$ tuần (13) & $<34$ tuần (6) & p-value & Test \\
\hline Tuối mẹ (năm) & $26,77 \pm 3,4$ & $27,5 \pm 6,2$ & $p>0,05$ & Chi-square \\
\hline \multicolumn{5}{|c|}{ Viêm âm đạo } \\
\hline Có & $12(75,00)$ & $4(25,00)$ & \multirow[b]{2}{*}{$p>0,05$} & \multirow[b]{2}{*}{ Fihser } \\
\hline Không & $1(33,33)$ & $2(66,67)$ & & \\
\hline Tuối thai PT & $19,73 \pm 1,80$ & $21,83 \pm 2,90$ & $p<0,05$ & Chi-square \\
\hline \multicolumn{5}{|c|}{ GD HCTMST } \\
\hline Giai đoạn II & $10(62,50)$ & $6(37,50)$ & \multirow[b]{2}{*}{$p>0,05$} & \multirow[b]{2}{*}{ Fihser } \\
\hline Giai đoạn IV & $3(100,00)$ & $0(0)$ & & \\
\hline Thời gian phâu thuật & $41,54 \pm 10,88$ & $37,50 \pm 4,18$ & $p>0,05$ & Mann-Whitney \\
\hline \multicolumn{5}{|c|}{ Vị trí bánh rau } \\
\hline Mặt trước & $9(75)$ & $3(25)$ & \multirow[b]{2}{*}{$p>0,05$} & \multirow[b]{2}{*}{ Fihser } \\
\hline Mặt sau & $4(57,14)$ & $3(42,86)$ & & \\
\hline \multicolumn{5}{|c|}{ SIUGR } \\
\hline Không & $4(44,44)$ & $5(44,6)$ & \multirow{2}{*}{$p>0,05$} & \multirow{2}{*}{ Fihser } \\
\hline Có & $9(90,00)$ & $1(10,00 \%)$ & & \\
\hline MPV ở thai đa ối & $90,85 \pm 11,33$ & $102,00 \pm 16,82$ & $p>0,05$ & Mann -Whitney \\
\hline Lượng ối hút ra & $538,46 \pm 253,44$ & $566,67 \pm 186,19$ & $p>0,05$ & Mann -Whitney \\
\hline Chiều dài CTC sau PT 48h & $37,79 \pm 3,93$ & $26,32 \pm 14,57$ & $p>0,05$ & Mann -Whitney \\
\hline
\end{tabular}


VIETNAM MEDICAL JOURNAL N01 - DECEMBER - 2021

\begin{tabular}{|c|c|c|c|c|}
\hline Chiều dài CTC sau PT 7 ngày & $37,61 \pm 4,63$ & $30,60 \pm 10,39$ & $\mathrm{P}>0,05$ & Mann -Whitney \\
\hline $\begin{array}{c}\text { Thay đối chiều dài CTC } \\
\text { sau PT 48h }\end{array}$ & $-6,80 \pm 22,84$ & $28,53 \pm 29,98$ & $\mathrm{P}<0,05$ & Chi-square \\
\hline $\begin{array}{c}\text { Thay đối chiều dài CTC } \\
\text { sau PT 7 ngày }\end{array}$ & $-7,98 \pm 33,81$ & $6,79 \pm 41,83$ & $\mathrm{p}>0,05$ & Chi-square \\
\hline
\end{tabular}

Nhận xét: Tuần tuối thai phầu thuật và độ giảm chiều dài CTC 48 giờ sau phấu thuật có liên quan tới sinh non dưới 34 tuần với $p<0,05$.

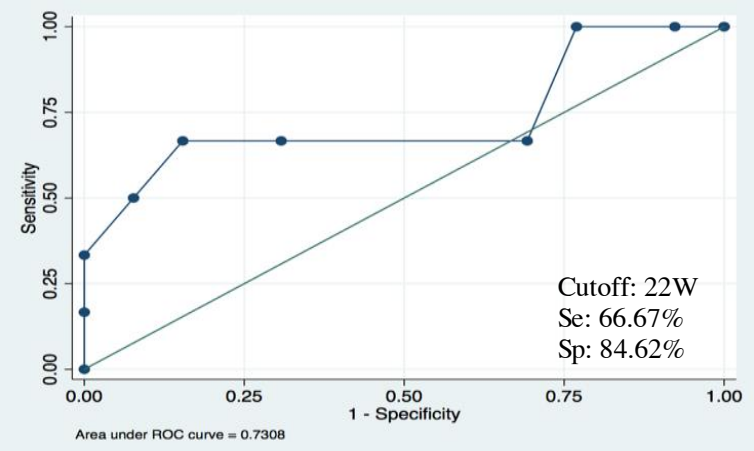

Hình 1a: Đường cong ROC biểu thị tuổi thai khi phẫu thuật và tiên lượng đẻ non trước 34 tuần

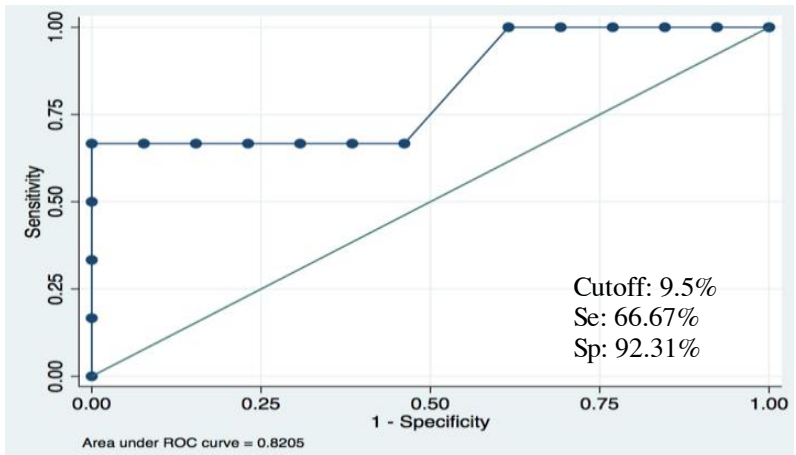

Hình 1b: Đường cong ROC biểu thị thay đổi CTC sau phẫu thuật 48 giờ với tiên lượng đẻ non trước 32 tuần.

Nhận xét: Hai yếu tố tiên lượng sinh non trước 34 tuân là tuần tuổi thai phẫu thuật (AUC 0,7308 ; se $5000 \%$, sp 92,31\%, PPV 75,00\%) và độ giảm chiêuu dài CTC sau phẫu thuật 48 giờ (AUC 8,205; se $66,67 \%$, sp $100 \%$, PPV $100 \%$ )

Bảng 5: Hồi qui đa biến sinh non trước 34 tuàn với các yếu tố

\begin{tabular}{|c|c|c|c|}
\hline Yếu tố & $\mathbf{R R}$ & CI 95\% & p-value \\
\hline Tuần thai phâu thuật $\geq 22$ tuần & 4,33 & $1,07-17,48$ & 0,0254 \\
\hline Thay đối chiều dài CTC sau PT 48 giờ $\geq 9.5 \%$ & 8,67 & $1,21-61,91$ & 0,0067 \\
\hline
\end{tabular}

Nhận xét: Phẫu thuật ở tuâan tuối thai trên 22 tuần tăng 4,33 lần nguy cơ đẻ non dưới 34 tuần và sự giảm chiêu dài CTC sau phẫu thuật 48 giờ trên 9,5\% tăng 8,67 lần nguy cơ đẻ non dưới 34 tuần.

\section{BÀN LUẬN}

Tỷ lệ sống sơ sinh sau phẫu thuật đông dây rốn chọn lọc điều trị HCTMST bằng laser quang đông của chúng tôi là $90,48 \%$ (bảng 1 ). Các báo cáo kết quả về đông dây rốn chọn lọcchọn lọc hiện nay thường là báo cáo kết quả chung các biến chứng của song thai một bánh rau 2 buồng ối. Kỹ thuật được báo cáo sử dụng nhiều là đốt sóng cao tần (RFA) và dao điện 2 cực. Laser quang đông mới được đưa vào các qui trình điều trị đông dây rốn chọn lọc nên không có nhiều dữ liệu báo cáo. Tỷ lệ sống sơ sinh được báo cáo trong các nghiên cứu đông dây rốn chọn lọc nói chung từ $70-90 \%$, và tỳ lệ này thấp hơn xung quanh $70 \%$ trong điêuu trị HCTMST. Tỷ lệ sống sơ sinh với kỹ thuật đông cầu nối mach khoảng 60 $70 \%$ nếu cả hai thai và $80-90 \%$ sống 1 thai [7], [8]. Như vậy tỷ lệ sống sơ sinh trong nghiên cứu của chúng tôi cao hơn so với các phương pháp điều trị khác.

Tuổi thai trung bình phẫu thuật là 20,3 tuần do HCTMST thường xuất hiện nhiều nhất ở quí II của thai kỳ. Thời gian phẫu thuật trung bình trong nghiên cứu của chúng tôi là 39,52 phút, gần xấp xỉ với phẫu thuật đông dây rốn chọn lọc dùng RFA báo cáo ở các nghiên cứu và thấp hớn so với phẫu thuật laser đông dây rốn chọn lọc trong báo cáo của Shiri Shinar là hơn 80 phút [7]. Phẫu thuật đông dây rốn chọn lọc là một phẫu thuật can thiệp, các dụng cụ đi vào trong buồng tử cung, thời gian phấu thuẩt lâu làm tăng nguy cơ võ̃ ối non và đẻ non sau phẫu thuật.

Chúng tôi không ghi nhận trường hợp nào có biến chứng trong quá trình thực hiện phấu thuật. Trong vòng 7 ngày sau phẫu thuật có 2 trường hợp thai lưu chiếm $6.06 \%$. Thai lưu sau phẫu thuật là một trong những biến chứng hay xảy ra sau phẫu thuật đông dây rốn chọn lọc và thường được giả thuyết do sự cắt đứt đột ngột tuần hoàn của một thai gây ảnh hưởng đến huyết động của thai còn lại. Các nghiên cứu công bố tỷ lệ này khoảng từ $10-15 \%$, xảy ra nhiều hơn sau phẫu thuật đông dây rốn chọn lọc do HCTMST, TAPS, sIURG [2]. Ngoài ra các biến 
chứng cũng hay gặp được mô tả ở các nghiên cứu trước đấy là ối võ non, thủng vách ngăn buồng ối.... cũng không ghi nhận trong nghiên cứu của chúng tôi. Chúng tôi cũng không ghi nhận biến chứng me nào sau phẫu thuật.

Tuổi thai trung bình kéo dài thêm 12,97 tuần, tuần thai trung bình lúc sinh là $34,70 \pm 4,33$ tuần. Kết quả trong nghiên cứu của chúng tôi tương ứng với kết quả trong nghiên cứu của Fatemeh và cộng sự về đánh giá hiệu quả của dùng sóng cao tần (RFA) trong phẫu thuật đông dây rốn chọn lọc nói chung của các trường hợp biến chứng của song thai một bánh rau hai buồng ối, và cao hơn đông dây rốn chọn lọc trong điều trị HCTMST bằng phương pháp khác như dao điện hai cực hay RFA (trung bình tuần thai lúc sinh 30 tuần) [8]. Tỷ lệ đẻ non trong nghiên cứu của chúng tôi dưới tuần 37 là $52,63 \%$, dưới 34 tuần là 31,57\%, tỷ lê này thấp hơn một số nghiên cứu đã công bố trước đấy là $70 \%$ và $50 \%$ [2], [4]. Các nghiên cứu cũng chỉ ra tỷ lệ đẻ non càng cao hơn ở nhóm đông dây rốn chọn lọc do HCTMST do ngoài những yếu tố nguy cơ cao của song thai, tình trạng đa ối của bệnh là yếu tố thuận lợi gây tăng nguy cơ. Đặc biệt trong các nghiên cứu, đông máu dây rốn chọn lọc bằng phương pháp laser là một phương pháp can thiệp đưa dụng cụ vào trong buồng ối và sẽ gây tăng nguy cơ sinh non khác với sử dụng phương pháp như RFA, không phẫu thuật nội soi buồng tử cung. Do vậy tỷ lệ đẻ non do phẫu thuật laser thường cao hớn do dùng phương pháp RFA [8]. Tuy nhiên, trong nghiên cứu của chúng tôi, tỷ lệ đẻ non thấp hơn đáng kể điều này có thể do chúng tôi thực hiện phẫu thuật ở tuân thai 16-26 thai kỳ, một số nghiên cứu công bố hiện nay về kết quả đồng dây rốn chọn lọc có thực hiện ở 3 tháng cuối thai kỳ, thời gian thực hiện phẫu thuật trong nghiên cứu của chúng tôi ngắn, phần lớn các sản phụ khoẻ mạnh không có biểu hiện doạ đẻ non hay có chiều dài cố tử cung ngắn trước phẫu thuật.

Tuy vậy, tỷ lệ sinh non trong nghiên cứu của chúng tôi cũng còn khá cao. Đây cũng là vấn đề rất được quan tâm bởi các nhà lâm sàng vì đẻ non làm tăng nguy cơ tử vong sơ sinh và biến chứng thần kinh, ảnh hưởng đến kết quả của phương pháp điều trị. Khi kiểm định đa biến tìm các yếu tố ảnh hưởng đến nguy cơ sinh non dưới 34 tuần, trong nghiên cứu của chúng tôi thì có 2 yếu tố có liên quan là tuần thai thực hiện phẫu thuật và sự thay đổi chiều dài cổ tử cung sau phẫu thuật 48 giờ. Với điểm cắt đã tìm được nếu phẫu thuật trên 22 tuần nguy cơ sinh non cao hơn 4,33 lần ( $95 \% \mathrm{CI}, 1.07$ - 17.48; $\mathrm{p}=0.0254)$ và nếu chiều dài cổ tử cung thay đổi so với trước phẫu thuật trên $9.5 \%$ thì nguy cơ sinh non tăng lên 8,67 lần $(95 \%$ CI $1.21-61.91 ; p=0.0067)$. Như vậy trong thực hành lâm sàng, chúng tôi khuyến cáo thực hiện đo chiều dài cổ tử cung thường qui trong qui trình phẫu thuật ở các thời điểm trước và sau mổ, đây là một yếu tố gợi ý để theo dõi nguy cơ sinh non của bệnh nhân. Ngoài ra, khi phẩu thuật ở các trường hợp tuần tuổi thai lớn, việc theo dõi sát và dự phòng điều trị doạ đẻ non có thể được cân nhắc thực hiện.

\section{KẾT LUẬN}

Phẫu thuật đông dây rốn chọn lọcchọn lọc bằng laser điều trị HCTMST trong nghiên cứu của chúng tôi có kết quả sống sơ sinh khá cao, ít biến chứng sau phẫu thuật. Yếu tố có thể tiên lượng việc đẻ non là tuần thai phẫu thuật và thay đổi chiều dài cổ tử cung sau phẩu thuật 48 giờ.

\section{TÀI LIÊU THAM KHẢO}

1. J. Akkermansa, S. H. P. Peetersa, F. J. Klumpera et al (2015). A worldwide survey of laser surgery for twin-twin transfusion syndrome. Ultrasound Obstet Gynecol, 45, 168 - 174.

2. J. Akkermansa, S. H. P. Peetersa, F. J. Klumpera et al (2015). Twenty-Five Years of Fetoscopic Laser Coagulation in Twin-Twin Transfusion Syndrome: A Systematic Review. Fetal Diagn Ther 38, 241-253.

3. J. S. Viral M. Pandya*, Claire Colmant, Yves Ville (2020). Current Practice and Protocols: Endoscopic Laser Therapy for Twin-Twin Transfusion Syndrome. Maternal-Fetal Medicine, 2:1,

4. M. Amol Malshe, L. K. M. Saul Snowise M.D., M.B.B.S., Noemi Boring., andD. O. Anthony Johnson, Michael W. Bebbington, M.D. M.H.Sc., Kenneth J. Moise Jr., M.D., Ramesha Papanna, M.D., M.P.H. (2017). Preterm delivery after fetoscopic laser surgery for twin-twin transfusion syndrome: etiology and its risk factors. Ultrasound Obstet Gynecol, 49 (5), 612-616.

5. $\mathbf{R}$ Townsend. anda. A. Khalil (2018). Ultrasound surveillance in twin pregnancy: An update for practitioners. ISOUG,

6. Quintero R.A, Morales W.J, Allen M.H et al (1999). Staging of twin-twin transfusion syndrome. J Perinatol, 19 (8 Pt 1), 550-555.

7. S. Shinar, S. Agrawal, D. El-Chaar et al (2021). Selective fetal reduction in complicated monochorionic twin pregnancies: A comparison of techniques. Prenat Diagn, 41 (1), 52-60.

8. F. Rahimi-Sharbaf, M. Ghaemi, A. A. Nassr et al (2021). Radiofrequency ablation for selective fetal reduction in complicated Monochorionic twins; comparing the outcomes according to the indications. BMC Pregnancy Childbirth, 21 (1), 189. 